\title{
Picosecond Laser Fabrication of the Riblet-Array Surface Texture on Ti64 Alloy Substrate
}

\author{
X. C. Wang and Y. C. Wan \\ Singapore Institute of Manufacturing Technology (SIMTech), A*STAR, 2 Fusionopolis Way, \#08-04, \\ Innovis, Singapore 138634 \\ E-Mail: xcwang@SIMTech.a-star.edu.sg
}

\begin{abstract}
In the paper, laser surface texturing process was studied systematically to fabricate riblet array surface structure on Ti64 substrate with $1.06 \mu \mathrm{m} 10 \mathrm{~W}$ ps laser which has a pulse duration of $10.3 \mathrm{ps}$. The optimum laser surface texturing process parameters were identified, under which the desired riblet-array textures were produced on Ti64 substrate with the required specifications in terms of dimension and quality. The fabricated riblets have a trapezoidal shape with a period of $60 \mu \mathrm{m}$ and riblet height of $30 \mu \mathrm{m}$ and a bottom surface roughness (Ra) of $2.115 \mu \mathrm{m}$. Compared with nontextured sample, the laser-fabricated riblets induced around a 10\% reduction in the drag force. Also, it was found that laser surface treatment did not induce any change on the microstructure of Ti64 during ps laser riblet surface texturing of Ti64 substrate. With XRD measurements, the laser riblettextured Ti64 surface was found to exhibit tensile stress of $87.5 \mathrm{MPa}$, which may be due to the heat shock from laser treatment resulting in larger d-spacing between lattice planes.
\end{abstract}

DOI: $10.2961 /$ jlmn.2019.03.0003

Keywords: picosecond laser, riblet array texture, Ti64, metallurgical microstructure, residual stress

\section{Introduction}

It is known that the turbulent flows increase the flowing drag in the fast flowing systems, where the wall friction losses is due to the turbulent momentum transfer in the viscous sublayer of turbulent flows [1]. The wall shear stress and the drag can be reduced by the proper riblet surface patterning with the correct orientation and dimensions, which is inspired by the shark skin. [2] When a certain type of riblets is fabricated on a surface, the viscous sublayer flowing in the cross flow direction is more impeded than in the longitudinal flow direction because the flow is forced to move in the channels between the riblets. Then the impeded cross flow induces a restricted vertical motion and thus decreased shear stress and skin friction. [3, 4]. Fig. 1 shows a schematic illustration of a riblet surface.

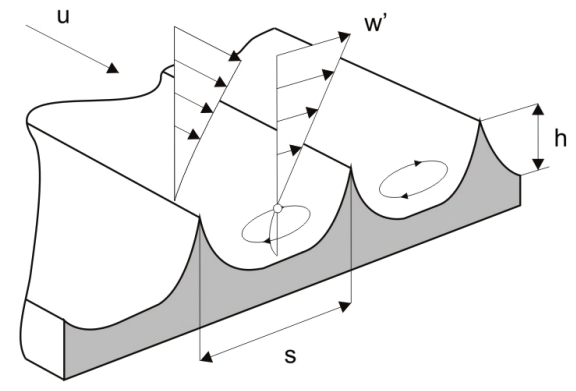

Fig. 1 Schematic of a riblet structure (adapted from the literature [2])

Usually, as shown in Fig, 1, the pitch between the riblets (s) should be approximately twice as large as the height (h) of the riblets: $\mathrm{h} / \mathrm{s}=0.5-0.6$. Also, the riblet shape influences the effectiveness of the drag reduction significantly. The riblets with very narrow sheet shape is ideal and can induce the largest wall shear stress reduction but is difficult to fabricate. The riblets with trapezoidal shape with an opening angle of 30 degree also showed very good results on the wall shear reduction and are much easier to fabricate. For aeroengine applications, the riblets have different periods for different engines and its period is also dependent on the positions within the engine. Approximately, the riblet period is ranging from several micrometers up to around $100 \mu \mathrm{m}$.

Various techniques have been developed for surface structuring to create the desired surface textures, which can be classified into 2 major categories, namely top-down processes such as lithographic process, template-based method [5], plasma treatment [6, 7] and laser surface micromachining process [8, 9], and bottom-up processes mainly consisting of self-assembly and self-organization processes $[10,11]$. As a top down approach, ultrafast picosecond (ps) laser is increasingly used as a tool for the surface structuring for improving the surface functional performance $[12,13]$ such as wettability control, improving the tribological properties, and optical properties, etc. due to its unique advantages such as its micrometric precision, non-contact process, selectivity, localizability, and minimum heat affected zone. By laser ablation with ultra short pulses in the pico- range, well controlled micro-scaled surface textures can be obtained. Hitherto, a lot of research studies have been conducted on laser surface texturing of different materials such as metals [14-18], silicon [19], and polymers $[20,21]$ for the modification of their wettability to hydrophobicity or even superhydrophobicity. A systematic review [22, 23] has been conducted on laser superhydrophobic surface fabrication processes. The mechanisms on wettability conversion of micro-nano structured metallic surfaces from super-hydrophilicity to superhydrophobicity have also been well reported [15, 24, 25]. Also, laser surface texturing was intensively investigated and applied on 
the metal substrates to improve the tribological properties of the sliding components, and cutting tools [26-31]. It has been demonstrated that the surface textures produced on cutting tools are able to improve the performance of the textured cutting tools in terms of friction coefficient reduction, trapping wear debris, storing lubricants, giving rise to reduced cutting forces and tool-chip contact length, decreasing the cutting chip friction, and lowering the cutting heat generation during the cutting processes, which ultimately lead to long tool life.

In the paper, we presented laser surface texturing process to fabricate high quality riblet array surface texture on Ti64 substrate with $1.06 \mu \mathrm{m} 10 \mathrm{~W}$ ps laser. The fabricated riblet surface texture has a period of $60 \mu \mathrm{m}$ and height of $30 \mu \mathrm{m}$. The wind tunnel testing result showed that the riblet-array surface texture fabricated on the aerofoil surface induced around a $10 \%$ reduction in the drag force compared with the non-textured aerofoil surface. Also, the material metallurgical micro-structure was characterized with no change compared with the original Ti64. And the residual stress of the laser riblet surface textured Ti64 samples was measured with XRD and exhibited tensile stress of 87.5 $\mathrm{MPa}$, which may be due to the heat shock from laser treatment resulting in larger $\mathrm{d}$-spacing between lattice planes.

\section{Experiments}

$1 \mathrm{~mm}$ thick Ti64 plate was used for laser riblet surface texturing. Before laser surface texturing, the samples first underwent sonication-cleaning with acetone and methanol. In the experiments, A TIME BANDWIDTH DUETTO ps laser system was employed to do the laser riblet surface structuring. The laser has Gaussian profiled spatial mode (TEM00) with a beam quality of M $<1.3$ and the beam divergence of less than $0.3 \mathrm{mrad}$. The laser wavelength is near-infrared $1.06 \mu \mathrm{m}$, the output power is up to $10 \mathrm{~W}$, and the laser pulse width is 10.3 ps. The pulse repetition frequency can be set at a minimum value of $50 \mathrm{kHz}$ and continuously tuned up to $8200 \mathrm{kHz}$. The incident laser beam was focused and manipulated by a galvo-scanner, which was equipped with a telecentric f-theta lens (Supplier: Unice E-O Services Inc; Model number: S4LFT4127-328) with a scan area of $50 \times 50 \mathrm{~mm}^{2}$. The focus length of the $\mathrm{f}-$ theta focus lens is $125 \mathrm{~mm}$. The linear polarized raw laser beam has a diameter of $7 \mathrm{~mm}\left(@ 1 / \mathrm{e}^{2}\right)$, which was focused and directed on to the sample surface with a beam diameter of $25 \mu \mathrm{m}$. The laser machining control software can produce various different machining patterns. The patterns can be lines, circular and rectangular shapes, and also hatched patterns, etc. The maximum scanning speed that the galvanometer scanner is capable of is $2000 \mathrm{~mm}$ per second. After laser treatment, the sample surfaces were characterized with optical microscope, the scanning electron microscopy (SEM) and 3D optical profilometer.

Also electropolishing was employed to etch different depth to measure depth profile of the residual stress, which was a suitable technique to remove surface material without introducing additional stresses to surface and was also able to precisely control the rate of material removal through optimizing current density during polishing and varying polishing time. The electropolishing was conducted using the following conditions:
- Electrolyte: $3 \mathrm{M} \mathrm{H}_{2} \mathrm{SO}_{4}$-methanol

- Counter-electrode: pure titanium (cathode)

- Pre-treatment cleaning

- 10 mins in $\mathrm{NaOH}$ solution

○ $10 \mathrm{~s}$ in $10 \% \mathrm{H}_{2} \mathrm{SO}_{4}$ solution

- $1.00 \mathrm{~A} / \mathrm{cm}^{2}$, various polishing time

- Post treatment

- $10 \mathrm{~s}$ in $10 \% \mathrm{HNO}_{3}$ solution

- $1 \mathrm{~min}$ in $70^{\circ} \mathrm{C} \mathrm{DI}$ water

Through controlling the etching time, the etching depth could be accurately controlled.

Then, the X-ray powder diffraction (XRD) (D8 Discover/Bruker Germany) was conducted on the laser textured samples for the residual stress analysis, where the copper source was used.

\section{Results and discussion}

Fig. 2 showed the designed patterns to be employed to produce the desired riblet surface texturing. The riblet surface patterns are produced through continuous line scanning of a regular periodic hatched pattern with the focused laser beam, where D is the hatching density, $\mathrm{W}$ is the groove width and $\mathrm{P}$ is riblet pattern period.

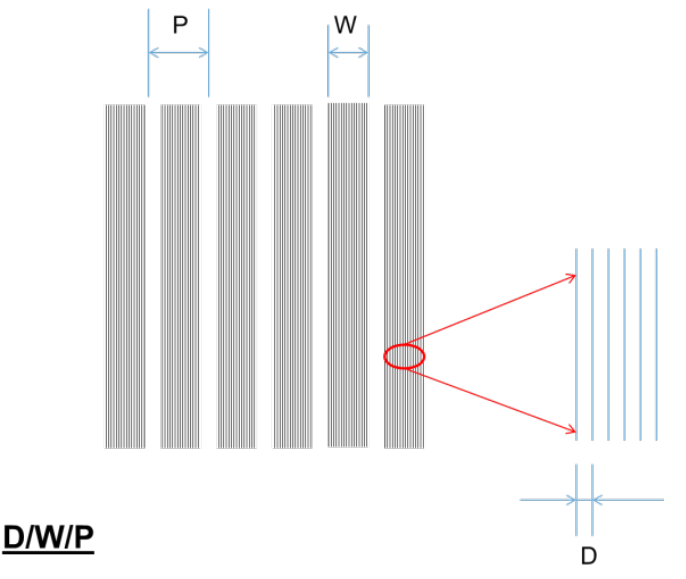

Fig. 2 Designed patterns for laser produced riblet surface texturing.

The laser processing parameters such as laser fluence, repetition rate, hatching pattern, scanning speed, pass number are identified as the key parameters for laser surface texturing process. These parameters affect the texture geometries such as feature size, depth, surface finish and thermal related issues such as material recast and heat affected zone. Through optimizing the laser parameters, we managed to achieve the desired riblet surface texturing.

First, laser surface riblet surface texturing were conducted under different laser fluences of $0.54 / 0.81 / 1.07 /$ $1.32 / 1.67 \mathrm{~J} / \mathrm{cm}^{2}$. Fig. 3 showed the fabricated riblet height and groove bottom roughness as a function of laser fluence. The other parameters were set at $1 \mathrm{MHz}$ repetition rate, scanning speed of $1000 \mathrm{~mm} / \mathrm{s}$ for 60 passes, and hatching density is $10 \mu \mathrm{m}$. The fabricated riblet textures have the riblet period of $150 \mu \mathrm{m}$ and groove width of $120 \mu \mathrm{m}$. It can be seen that the riblet height and bottom roughness $\mathrm{Ra}$ is increased with increasing the laser fluence as shown in Fig. 3 . The lower the laser fluence is used, the lower the bottom surface roughness of $\mathrm{Ra}$. 


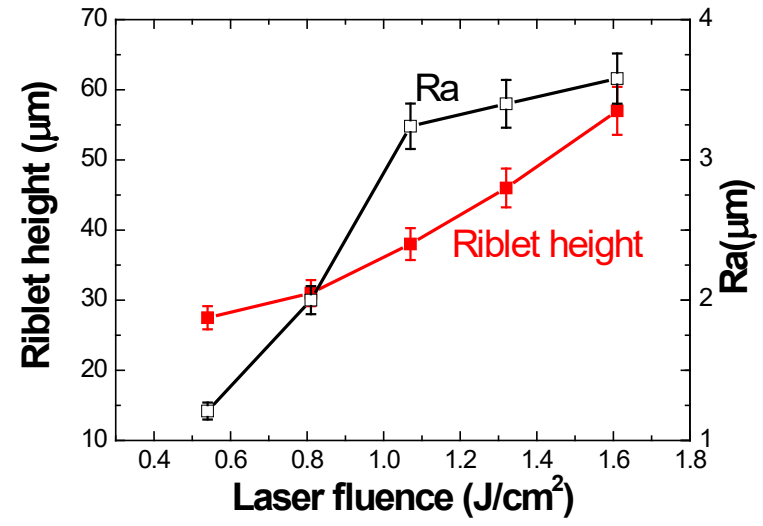

Fig. 3 Riblet height and bottom roughness as a function of laser fluence

So, to have a lower surface roughness, laser surface texturing was conducted at a lower laser fluence of 0.54 $\mathrm{J} / \mathrm{cm}^{2}$ for different laser passes. Fig. 4 showed the riblet height and surface roughness $\mathrm{Ra}$ of the fabricated riblet textures as a function of pass number. The other parameters are set at a laser fluence of $0.54 \mathrm{~J} / \mathrm{cm}^{2}$, repetition rate of $1 \mathrm{MHz}$, scanning speed of $1000 \mathrm{~mm} / \mathrm{s}$, and hatching density of $10 \mu \mathrm{m}$. The fabricated riblet has a period of 150 $\mu \mathrm{m}$ and a groove width of $120 \mu \mathrm{m}$. From Fig. 4, it can be seen that the riblet height is linearly increased with increasing the pass number whereas the groove bottom roughness $\mathrm{Ra}$ is almost not changing. So, more the pass number is used, larger the riblet height with a constant lower surface roughness $\mathrm{Ra}$ is achieved.

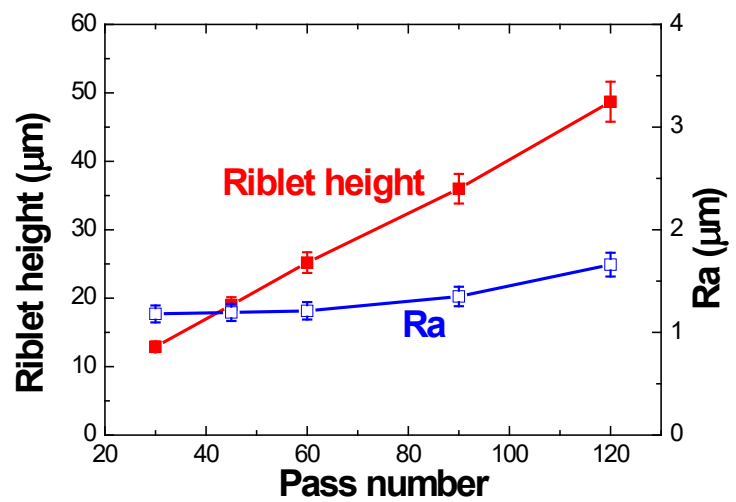

Fig. 4. Riblet height and bottom roughness as a function of pass number

The effects of the scanning speed were investigated on the fabricated riblet surface texture in terms of bottom surface roughness. Fig. 5 showed the laser fabricated riblet textures at different scanning speed for different pass number of (a). $1000 \mathrm{~mm} / \mathrm{s}$ for 60 passes (b). $500 \mathrm{~mm} / \mathrm{s}$ for 30 passes; and (c). $250 \mathrm{~mm} / \mathrm{s}$ for 15 passes and (d). $125 \mathrm{~mm} / \mathrm{s}$ for 8 passes with the same effective processing speed of $16.67 \mathrm{~mm} / \mathrm{s}$ for all scanning speeds. The other laser parameters are set at a laser fluence of $0.54 \mathrm{~J} / \mathrm{cm}^{2}$, repetition rate of $1 \mathrm{MHz}$, hatching density of $5 \mu \mathrm{m}$. The fabricated riblet has a period $60 \mu \mathrm{m}$ and the groove width of $50 \mu \mathrm{m}$. From Fig. 5, it was observed that the higher the scanning speed, the lower the Ra at the bottom of the grooves, also, less the heat effect.

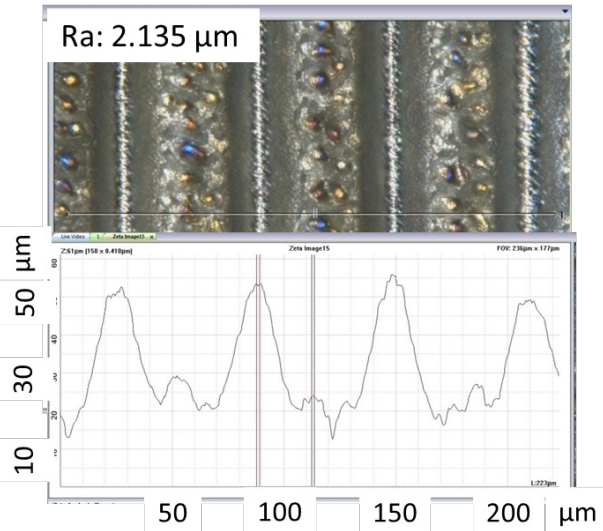

(a)

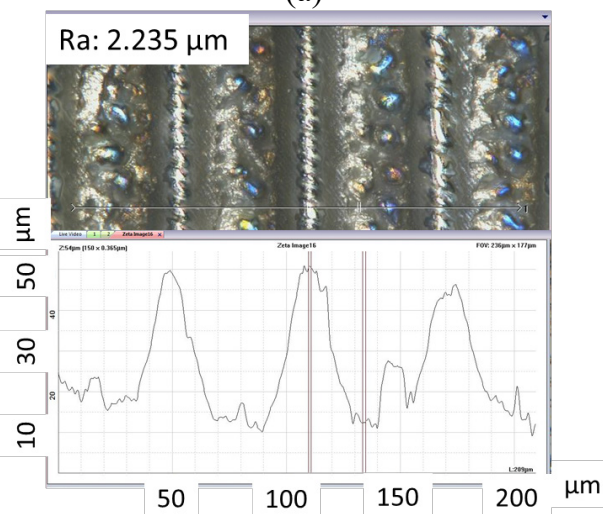

(b)

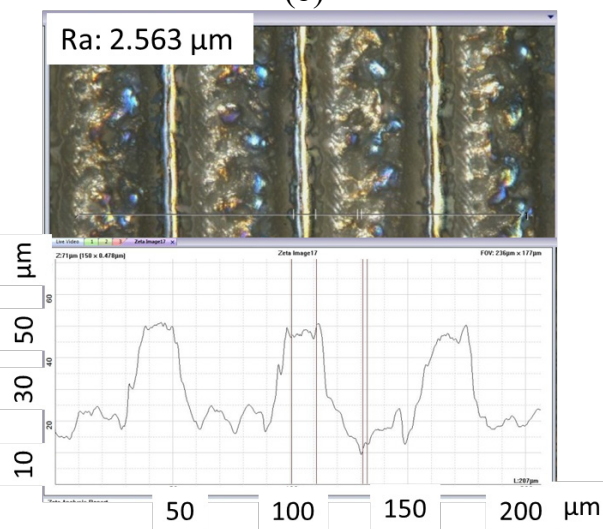

(c)

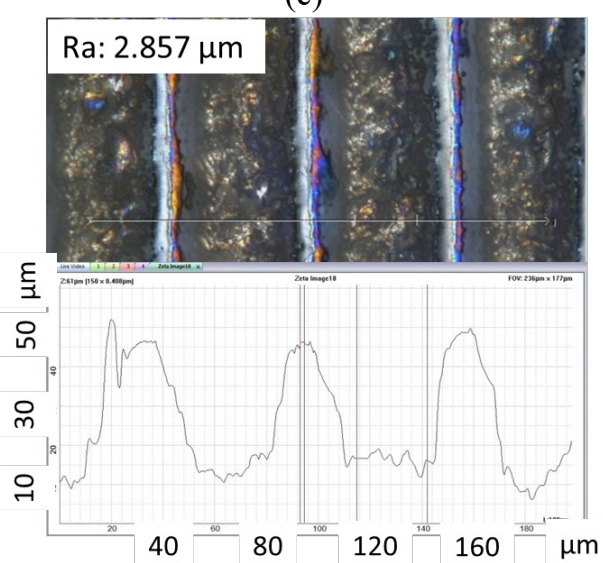

(d)

Fig. 5 Ps laser fabricated riblet surface textures at different scanning speed of (a). $1000 \mathrm{~mm} / \mathrm{s}$ for 60 passes (b). $500 \mathrm{~mm} / \mathrm{s}$ for 30 passes; and (c). $250 \mathrm{~mm} / \mathrm{s}$ for 15 passes and (d). $125 \mathrm{~mm} / \mathrm{s}$ for 8 passes 


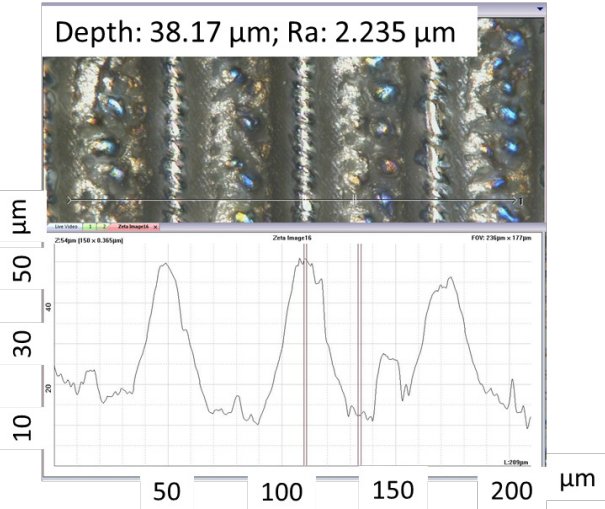

(a)

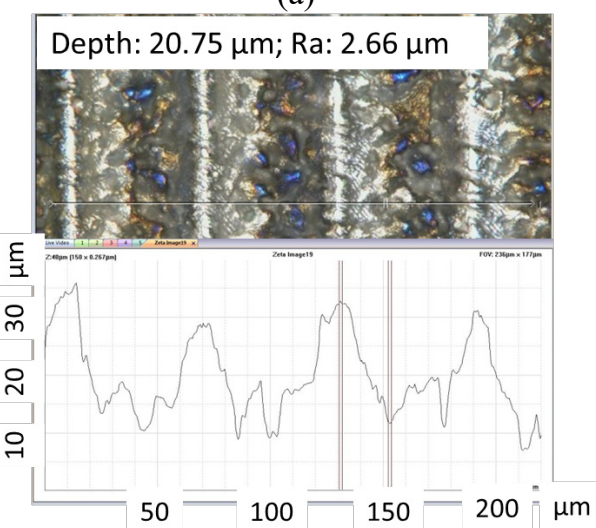

(b)

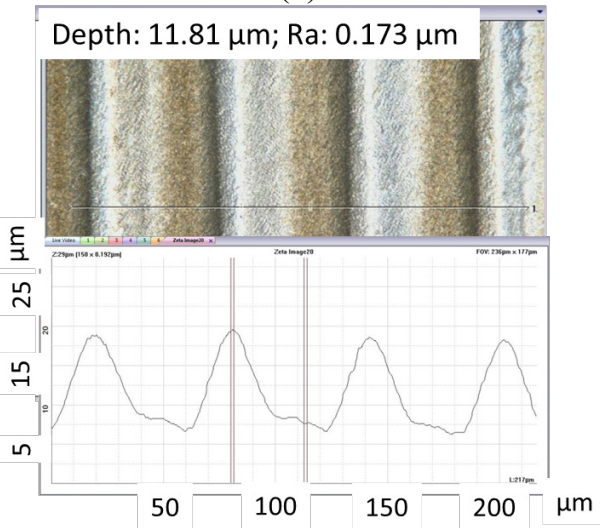

(c)

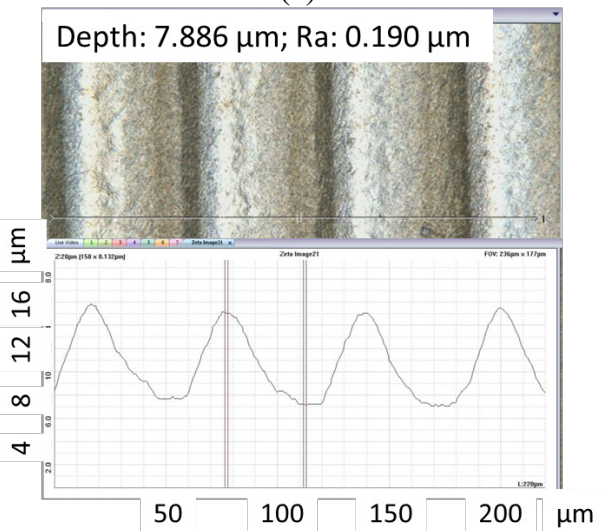

(d)

Fig. 6 Ps laser fabricated riblet surface textures at different repetition rate (a) $1 \mathrm{MHz}$ (b) $500 \mathrm{kHz}$ (c) $200 \mathrm{kHz}$ (d) $100 \mathrm{kHz}$
Fig. 6 showed the laser fabricated riblet textures at different repetition rates. The other parameters are set at a laser fluence of $0.54 \mathrm{~J} / \mathrm{cm}^{2}$, scanning speed of $500 \mathrm{~mm} / \mathrm{s}$ for 30 pass number and hatching density of $5 \mu \mathrm{m}$. The fabricated riblet has a period of $60 \mu \mathrm{m}$ and the groove width of $50 \mu \mathrm{m}$. From Fig. 6, it was found that the higher the repetition rate, larger the ablation depth and the larger the Ra. So, the high repetition rate $(1 \mathrm{MHz})$ is preferred to achieve high processing efficiency and at the same time to have an acceptable surface roughness.

Fig. 7 showed the laser fabricated riblet textures with 2 different hatching densities. The other parameters are set to be laser fluence of $0.54 \mathrm{~J} / \mathrm{cm}^{2}$, repetition rate of $1 \mathrm{MHz}$, scanning speed of $500 \mathrm{~mm} / \mathrm{s}$ for 30 pass number. The fabricated riblet has a period of $60 \mu \mathrm{m}$ and the groove width of $50 \mu \mathrm{m}$. From Fig. 7, it was found that the higher the hatching density, the larger the ablation depth and the lower the Ra.

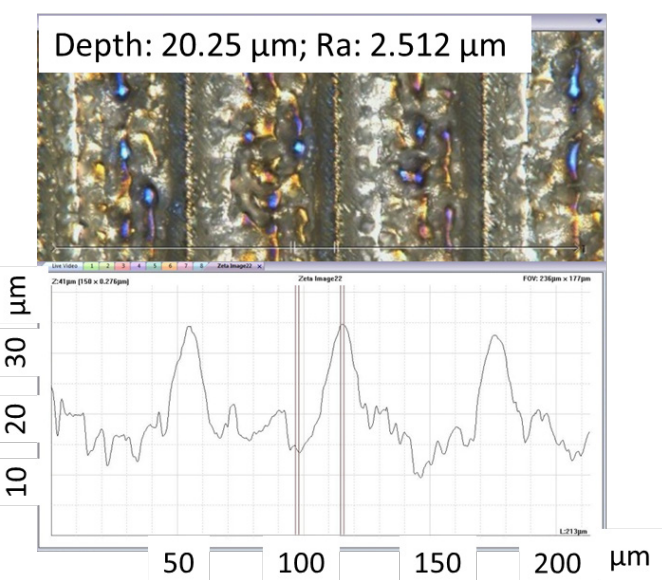

(a)

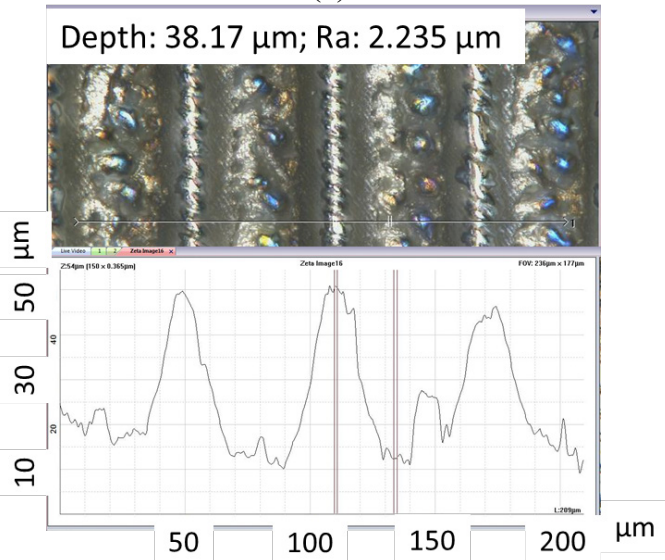

(b)

Fig. 7 Ps laser fabricated riblet surface textures at different hatching density (a) $10 \mu \mathrm{m}$ and (b) $5 \mu \mathrm{m}$

Based the above experimental results and discussion, the optimum laser parameters for fabricating desired riblet surface textures in terms of high processing efficiency and surface finish were identified as follows:

- Rep rate: $1 \mathrm{MHz}$

- Laser fluence: $0.54 \mathrm{~J} / \mathrm{cm}^{2}$

- Hatching density: $5 \mu \mathrm{m}$

- Scanning speed: $1000 \mathrm{~mm} / \mathrm{s}$

- Pass number: 60 
With the obtained optimum laser parameters, the riblet surface texture was fabricated on the aerofoil coupon as shown in Fig. 8, with the following measured dimensions:

- Riblet period : $60 \mu \mathrm{m}$

- Riblet height (Peak-trough): $30.53 \mu \mathrm{m}$

- Ra: $2.155 \mu \mathrm{m}$

The total fabrication time including part positioning and alignment was $880 \mathrm{~min}$ for the area of $37.17 \mathrm{~cm}^{2}$. So, the production time for unit area riblet texturing is 23.68 $\min / \mathrm{cm}^{2}$.

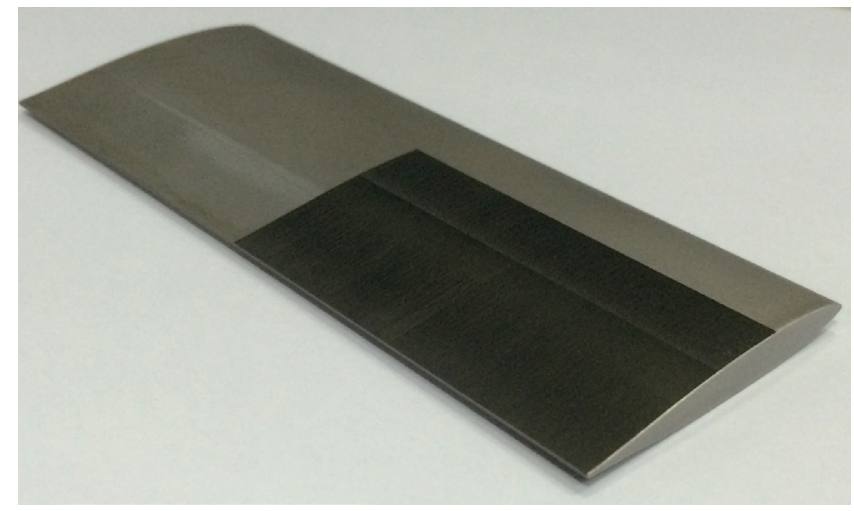

(a)

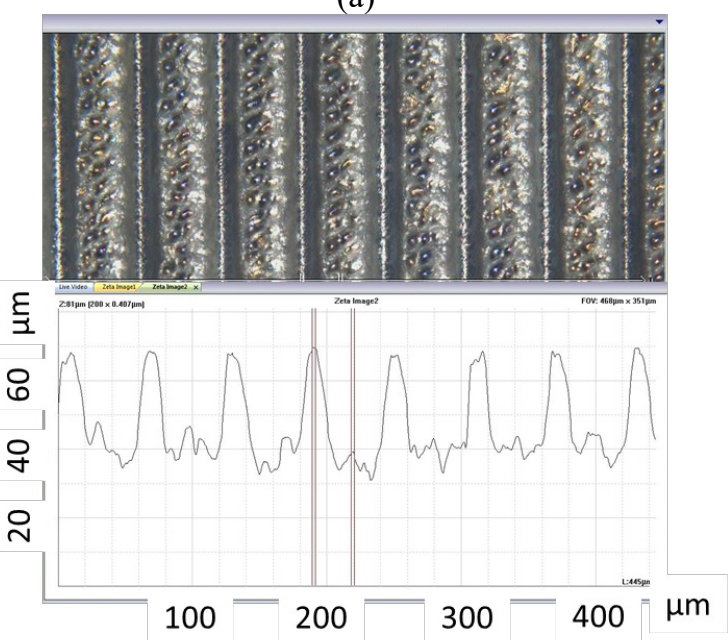

(b)

Fig. 8 Laser riblet surface textured aerofoil coupon (a) and measured riblet texture profile (b)

The wind tunnel testing was conducted on the laser riblet-textured aerofoil coupon. As shown in Fig. 9, the testing result showed that compared with non-textured area, at low Reynolds number the riblets induce around a $10 \%$ reduction in drag, indicating that the riblet-array surface texture is quite effective in reducing the friction drag.

Fig. 10 showed the cross-sectional microstructure images on riblet area and the area away from riblet of the laser riblet textured samples. The area away from riblet can be regarded as the original Ti64 without any treatment. The microstructures are characterized by $\alpha$ and $\beta$ phases with the lighter part showing the $\alpha$ grains and the darker parts showing the $\beta$ grains.

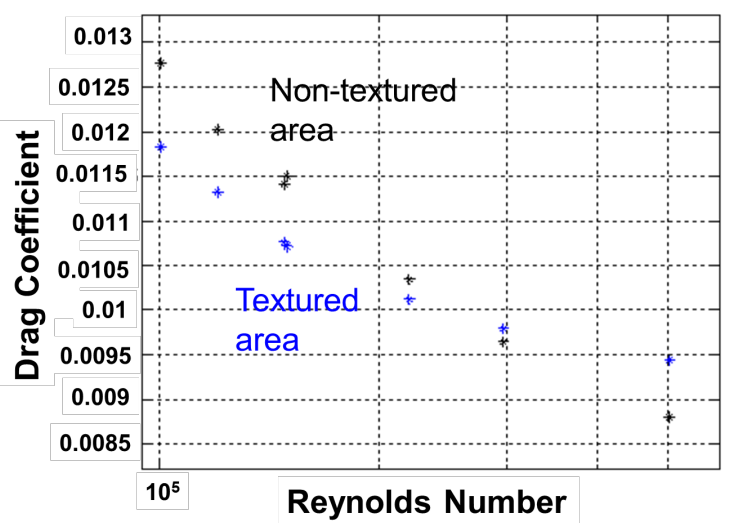

Fig. 9 the measured drag coefficient as a function of Reynolds number on laser textured \& non-textured aerofoil coupon

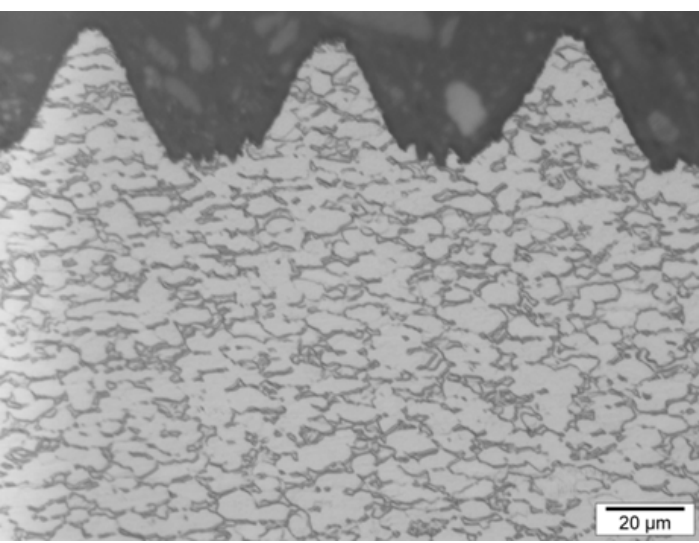

(a)

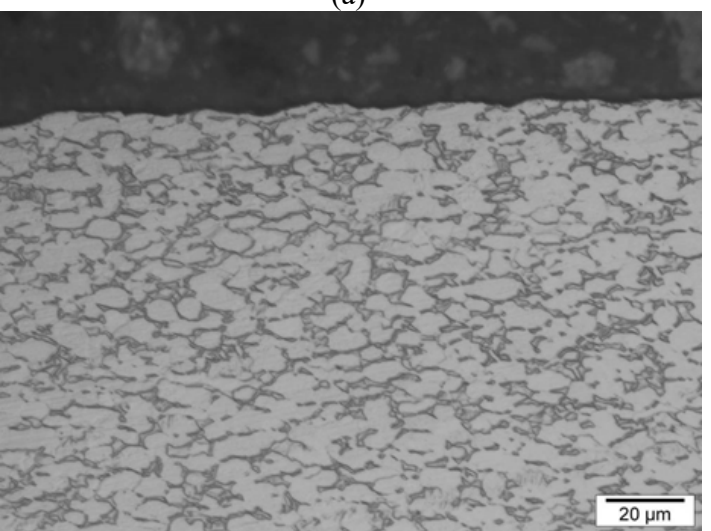

(b)

Fig. 10. The microstructure images on the laser riblet textured samples, (a) riblet area, (b) area away from riblet

As shown in Fig. 10, the microstructure in the riblet pattern area is almost same as the one in the area away from riblet, indicating no changing in terms of microstructure pattern, grain size, and its distribution. It can be clearly seen that the microstructures are consistent and no change throughout the sample from the riblet tip to the area far away from the laser treated area. The result indicated that the laser riblet texturing process is not causing any change on the microstructures and phase change of the laser treated surface area as compared with the area away from the riblet area. So, there is negligible heat effect on the microstructures of the Ti64 substrate during laser surface riblet texturing process. 


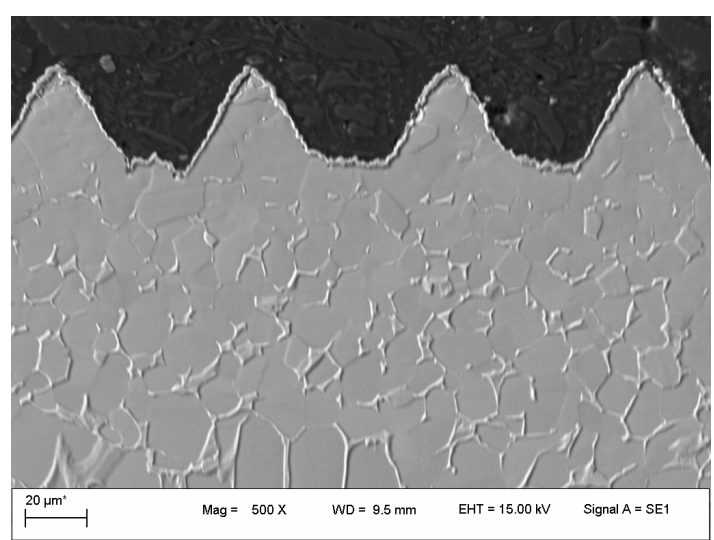

(a)

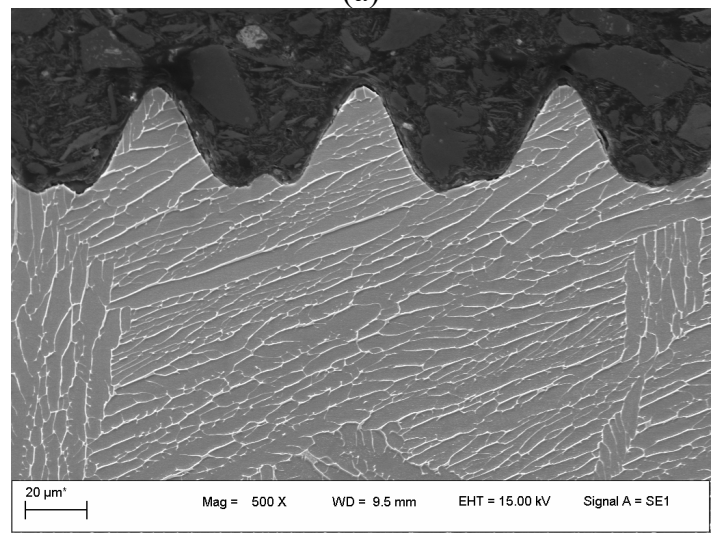

(b)

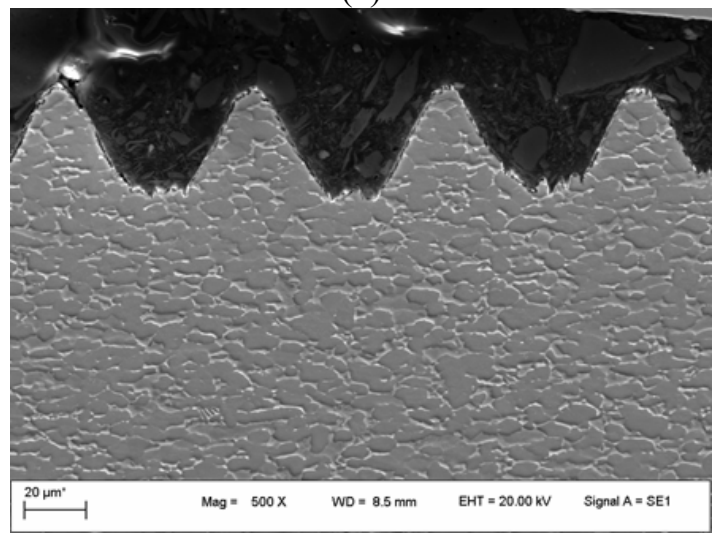

(c)

Fig. 11. the SEM images on the microstructure of laser textured Ti64 heat-treated with riblet texture side; (a) facing up (b) facing down (c) no furnace heating

In order to further verify no significant heat effect on the sample during laser surface texturing process, the laser textured samples were heat treated at a high temperature in the vacuum oven to see the effects of furnace heat treatment on the microstructures. The sample was heat-treated at $1050^{\circ} \mathrm{C}$ for 1 hour, then cooled with a cooling rate of $15^{\circ} \mathrm{C}$ per second. The samples were put in the oven with 2 ways: one was put with riblet texture side facing up and bottom side contacting the metal holder, the other one was put with riblet texture side facing down to contact the metal holder. Fig. 11 showed the effects of furnace heat treatment on the microstructure of the samples. The microstructure of laser riblet-textured Ti64 with no furnace heat treatment was also put in (Fig. 11 (c)) for comparison. It was noticed that the microstructure of laser textured Ti 64 without fur- nace heat treatment was quite different from the microstructures of furnace heat treated samples in terms of microstructure pattern, grain size, and its distrubution. For the heat-treated sample with riblet texture side facing up, the fine grains formed at edge tip area compared with the central bulk area due to its slower cooling rates. For the sample placed with laser treated side face down, the faster cooling rates retain the same microstructures as central bulk area as shown in Fig. 11 (b), where the $\alpha$ lamellae was separated by ribs of the $\beta$ grains. The different cooling rates were believed to be the reason to induce the different microstructures in the riblet tip area as shown in Fig. 11 (a) \& (b). [32] This finding further verified that laser surface texturing process did not induce any change for the microstructure of Ti64. So, there was negligible heat effect during ps laser riblet surface texturing of Ti64 aerofoil due to its ultra-short pulse duration.

Also, the residual stress was investigated as a function of depth on the laser textured Ti64 substrate. Fig. 12 showed one scanned XRD spectrum on Ti64, where the phase ID totally matches Ti64 sample and the inset showed rocking curves obtained at different $\psi$ angles. The fitting parameters for residual stress analysis were the peak position $2 \theta$ of $141.7^{\circ}$; Young modulus of $113 \mathrm{GPa}$ and Poisson of 0.32 . Fig. 13 showed the derived strain as a function of $\operatorname{Sin} 2 \Psi$, where linear relationship suggested no shear stress component and positive slope indicated tensile stress.

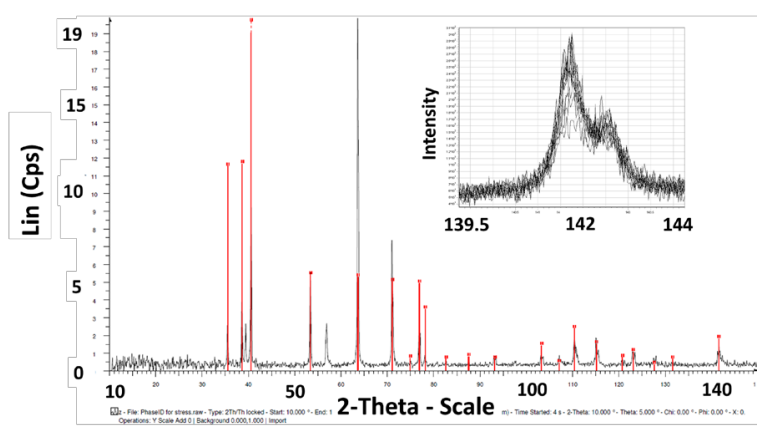

Fig. 12 Scanned XRD spectrum on Ti64, the inset shows rocking curves at about $2 \theta=141.7^{\circ}$ obtained at different $\psi$ angles

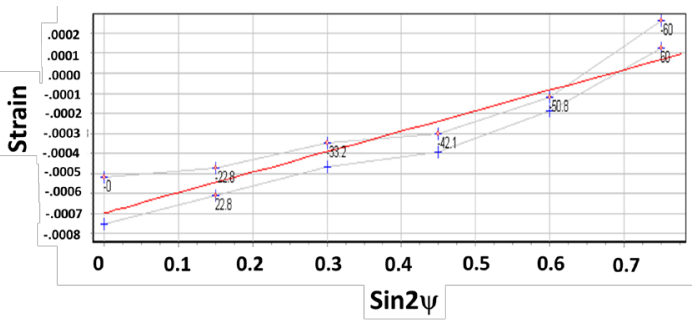

Fig. 13 The derived strain as a function of $\operatorname{Sin} 2 \Psi$

With XRD, the residual stress was measured on pristine sample and the laser riblet-textured Ti64 sample with different etched depths. Fig. 14 showed the measured residual stress as a function of the etched depth. As shown in Fig. 14 , it was found that the pristine sample surface exhibited compressive stress of $-38.5 \mathrm{MPa}$ and after laser treatment, the samples surface exhibited tensile stress of $87.5 \mathrm{MPa}$, which may be due to the heat shock from laser treatment resulting in larger d-spacing between lattice planes [33, 34]. 
Then the residual stress shifted from tensile to compressive when going deeper into laser processed sample and gradually becoming closer to the bulk stress value.

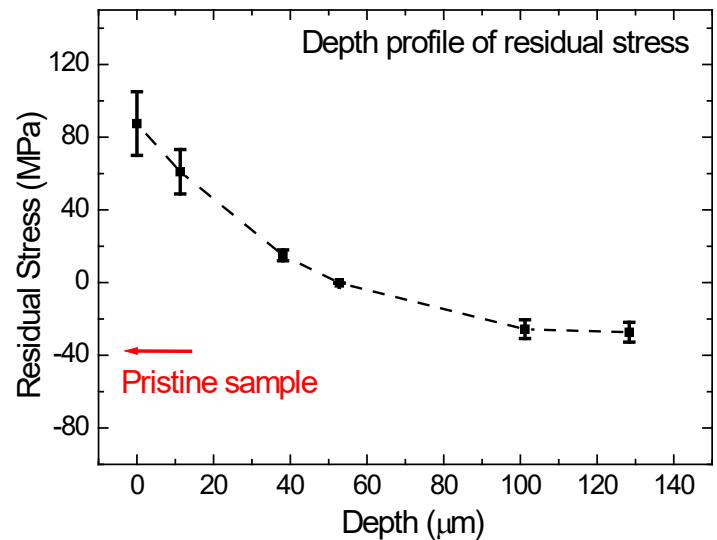

Fig. 14 The measured residual stress as a function of depth on laser treated Ti64 substrate

\section{Conclusion}

The Ps laser riblet surface texturing was conducted on Ti 64 substrates. The effects of various laser parameters on the riblet texture fabrication such as laser fluence, pass number, scanning speed, repetition rate and hatching density were investigated and the optimum laser texturing parameters were identified. Laser riblet texturing on the curved Ti 64 aerofoil coupon was demonstrated. Compared with non-textured area, the laser fabricated riblets induced around a $10 \%$ reduction in friction drag. It was also found that laser riblet surface texturing did not induce any change for the microstructure of Ti64 during ps laser riblet surface texturing of Ti64 aerofoil. Based on XRD measurements, the pristine sample surface exhibited compressive stress of $-38.5 \mathrm{MPa}$ and after laser treatment, the samples surface exhibited tensile stress of $87.5 \mathrm{MPa}$, which may be due to the heat shock from laser treatment resulting in larger d-spacing between lattice planes. Then the residual stress shifted from tensile to compressive when going deeper into laser processed sample and becoming closer to the bulk stress value.

\section{Acknowledgments}

The authors would like to thank Ms Ma Cho Cho Khin for her help with XRD characterization. They would also like to thank the Agency for Science, Technology and Research (A*STAR) of Singapore for financial support.

\section{References}

[1] C. C. Büttner and U. Schulz: Smart Mater, Struct., 20, (2011) 094016.

[2] D. W. Bechert, M. Bruse, W. Hage and R. Meyer: Naturwissenschaften, 87, (2000) 157.

[3] D. W. Bechert and M. Bartenwerfer: J. Fluid Mech., 206, (1989) 105.

[4] K. Oehlert, J. R. Seume, F. Siegel, A. Ostendorf, B. Wang, B. Denkena, T. Vynnyk, E. Reithmeier, W. Hage, K. Knobloch and R. Meyer: Proc. IMECE200743457 (Seattle, WA) vol 1, (2000) p. 25.

[5] J. Li, J. Fu, Y. Cong, Y. Wu, L. J. Xue and Y. C. Han: Appl. Surf. Sci., 252, (2006) 2229.
[6] S. H. Kim, J. H. Kim, B. K. Kang and H. S. Uhm: Langmuir, 21, (2005) 12213.

[7] K. Teshima, H. Sugimura, Y. Inoue, O. Takai and A. Takano: Appl. Surf. Sci., 244, (2005) 619.

[8] R. M. Wagterveld, C. W. J. Berendsen, S. Bouaida and J. Jonsmann: Langmuir, 22, (2006) 10904.

[9] W. Wong, K. Chan, K. W. Yeung and K. S. Lau: Journal of Materials Processing Technology, 132, (2003) 114.

[10] S. A. Kulinich and M. Farzaneh: Surf. Sci., 573, (2004) 379.

[11]D. Schondelmaier, S. Cramm, R. Klingeler, J. Morenzin, C. Zilkens and W. Eberhardt: Langmuir, 18, (2002) 6242.

[12]F. Siegel, V. Schütz, U. Stute and R. Kling: ICALEO, (2010) p. 753 .

[13] X. C. Wang, B. Wang, H. Xie, H. Y. Zheng and Y. C. Lam: J. Phys. D: Appl. Phys., 51, (2018) 115305.

[14] Y. Vorobyev and C. L. Guo: J. Appl. Phys., 117, (2015) 033103.

[15] A. M. Kietzig, S. G. Hatzikiriakos and P. Englezos: Langmuir, 25, (2009) 4821.

[16] M. Tang, V. Shim, Z. Y. Pan, Y. S. Choo and M. H. Hong: J. Laser Micro/Nanoeng., 6, (2011) 6.

[17] A. M. Kietzig, M. N. Mirvakili, S. Kamal, P. Englezos and S. G. Hatzikiriakos: J. Adhes. Sci. Technol., 25, (2011) 2789

[18] S. Moradi, S. Kamal, P. Englezos and S. G. Hatzikiriakos: Nanotechnology, 24, (2013) 415302.

[19] T. H. Her, R. J. Finlay, C. Wu, S. Deliwala and E. Mazur: Appl. Phys. Lett., 73, (1998) 1673.

[20]B. Wang, X. C Wang, H. Y. Zheng and Y. C. Lam: Nanomaterials, 5, (2015) 1442.

[21] S. F. Toosi, S. Moradi, S. Kamal and S. G. Hatzikiriakos: Appl. Surf. Sci., 349, (2015) 715.

[22]F. Chen, D. Zhang, Q. Yang, J. Yong, G. Du, J. Si, F. Yun and X. Hou: ACS Appl. Mater. Interfaces, 5, (2013) 6777.

[23] J. Long, P. Fan, D. Gong, D. Jiang, H. Zhang, L. Li and M. Zhong M: ACS Appl. Mater. Interfaces, 7, (2015) 9858.

[24] J. Long, M. Zhong, P. Fan, D. Gong and H. Zhang: J. Laser Appl., 27, (2015) S29107.

[25] W. Geng, A. Hu and M. Li: Appl. Surf. Sci., 263, (2012) 821.

[26] J. Bonse, S. Kirner, M. Griepentrog, D. Spaltmann and J. Krüger: Materials, 11, (2018) 801.

[27] C. Gachot,, A. Rosenkranz, S. M. Hsu, and H. L. Costa: Wear, 372, (2017) 21.

[28] M. P. A. B. Bertolete, Á. R. Machado, R. E. Samad, N. D. Vieira, R. Vilar and W. d. Rossi: The International Journal of Advanced Manufacturing Technology, 98, (2018) 2653.

[29]D. Ye, Y. Lijun, C. Bai, W. Xiaoli, W. Yang and X. Hui: The International Journal of Advanced Manufacturing, 96, (2018) 4367.

[30] S. K. Mishra, S. Ghosh and S. Aravindan: Precision Engineering, 56, (2019) 370.

[31]A. Rosenkranz, P. G. Grützmacher, C Gachot, and H. L. Costa: Advanced Engineering Materials, 21 (2019) 1900194. 
[32] R. Reham, A. N. Adel and H. A. H. Abdel: Journal of Metallurgical Engineering (ME), 2, (2013) 48.

[33] R. Su, L. Li, Y. D. Wang, Z. H. Nie, Y. Ren, X. Zhou and J. Wang: AIP ADVANCES, 8, (2018) 055126.
[34] M. Tatiana, A. Katia, J. Haubrich, G. Requena, and G. Bruno: Metals, 9, (2019) 261.

(Received: May 12, 2019, Accepted: November 4, 2019) 